\title{
A Systematic Review of the Impact of Physicians' Occupational Well-Being on the Quality of Patient Care
}

\author{
Renée A. Scheepers • Benjamin C. M. Boerebach • \\ Onyebuchi A. Arah • Maas Jan Heineman • \\ Kiki M. J. M. H. Lombarts
}

Published online: 3 March 2015

(C) The Author(s) 2015. This article is published with open access at Springerlink.com

\begin{abstract}
Background It is widely held that the occupational well-being of physicians may affect the quality of their patient care. Yet, there is still no comprehensive synthesis of the evidence on this connection.

Purpose This systematic review studied the effect of physicians' occupational well-being on the quality of patient care. Methods We systematically searched PubMed, Embase, and PsychINFO from inception until August 2014. Two authors independently reviewed the studies. Empirical studies that explored the association between physicians' occupational wellbeing and patient care quality were considered eligible. Data were systematically extracted on study design, participants, measurements, and findings. The Medical Education Research Study Quality Instrument (MERSQI) was used to assess study quality.
\end{abstract}

Electronic supplementary material The online version of this article (doi:10.1007/s12529-015-9473-3) contains supplementary material, which is available to authorized users.

R. A. Scheepers $(\bowtie) \cdot$ B. C. M. Boerebach • O. A. Arah •

M. J. Heineman • K. M. J. M. H. Lombarts

Professional Performance Research Group, Center for

Evidence-Based Education, Academic Medical Center, University of

Amsterdam, Meibergdreef 9, PO Box 22700, 1100

DE Amsterdam, The Netherlands

e-mail: r.a.scheepers@amc.nl

O. A. Arah

Department of Epidemiology, The Fielding School of Public Health, University of California, Los Angeles (UCLA), Los Angeles, CA, USA

O. A. Arah

UCLA Center for Health Policy Research, Los Angeles, CA, USA

M. J. Heineman

Academic Medical Center, University of Amsterdam, Amsterdam, The Netherlands
Results Ultimately, 18 studies were included. Most studies employed an observational design and were of average quality. Most studies reported positive associations of occupational well-being with patient satisfaction, patient adherence to treatment, and interpersonal aspects of patient care. Studies reported conflicting findings for occupational well-being in relation to technical aspects of patient care. One study found no association between occupational well-being and patient health outcomes.

Conclusions The association between physicians' occupational well-being and health care's ultimate goal-improved patient health - remains understudied. Nonetheless, research up till date indicated that physicians' occupational well-being can contribute to better patient satisfaction and interpersonal aspects of care. These insights may help in shaping the policies on physicians' well-being and quality of care.

Keywords Occupational well-being · Job satisfaction · Physicians · Quality of patient care · Patient satisfaction

\section{Introduction}

Well-being of physicians is a growing concern $[1,2]$. Compared to the general working population, many physicians suffer from burnout [3-5], as they deal with high levels of work strain and emotional demands [2]. Physicians' wellbeing is vital not only to the individual physician, but also to their ability to provide high-quality patient care [2]. That is, research indicated that physicians who suffer from burnout provide less adequate patient care [6-8] and low levels of physicians' well-being could lead to suboptimal performing health care systems [2]. Reversely, physicians with higher levels of well-being tend to provide better patient care [9]. In 
particular, higher levels of physicians' satisfaction or commitment with work are associated with higher levels of patient satisfaction as well as better prevention and disease management by physicians $[10,11]$.

High levels of work-related well-being can be conceptualized as occupational well-being, which is defined as a positive experience with or evaluation of one's work [12, 13], involving satisfaction, commitment, involvement, or engagement [14-16]. As such, occupational well-being distinctively involves positive indicators of work experience, instead of negative indicators, such as burnout. Naturally, occupational wellbeing is vital to the daily practice of physicians and physicians can be energized and satisfied in providing their patients with the most appropriate treatment $[17,18]$. Indeed, many physicians experience high levels of job satisfaction and work engagement $[19,20]$.

Most research on physicians' well-being has so far focused on negative indicators. In line with the positive psychology approach [21, 22], it would provide comprehensive insight when additionally understanding the impact of positive occupational well-being of physicians. Research indicated that physicians with higher levels of work satisfaction deliver better patient care, possibly because they are motivated to make every effort for their patients [9]. Occupational well-being is accompanied by more positive emotions, energy, and concentration $[12,13,23]$, and it is likely that physicians who experience more well-being, energy, and concentration in their work can more easily dedicate their full attention to patients' needs and provide them with optimal care. However, there is still no comprehensive synthesis of the evidence on the connection between physicians' occupational well-being and patient care quality. Therefore, it remains unclear if and which aspects of patient care quality are affected by occupational well-being of physicians. We conducted a systematic review of the effects of physicians' occupational well-being on the different aspects of quality of care.

\section{Method}

Before starting the review, all authors agreed upon the eligibility criteria, search strategy, study selection, data extraction, and quality assessment. The review process was reported according to the Preferred Reporting Items for Systematic Reviews and Meta-Analyses (PRISMA) standards [24].

\section{Eligibility Criteria}

Studies were considered to be eligible, when they examined the association between physicians' occupational well-being and the quality of patient care. This resulted in the following eligibility criteria. First, the study included empirical data; non-empirical articles, such as letters, comments, and editorials, were excluded. Second, physicians had to comprise the entire sample or results had to be available for physicians as a subgroup. Third, in order to study our research question on the impact of occupational well-being on patient care quality, we included only articles that conceptualized occupational well-being as predictor or exposure variable and patient care quality as the outcome variable. Non-English language articles were not included.

\section{Data Sources and Searches}

We searched the electronic databases MEDLINE, Embase, and PsycINFO from inception until August 12, 2014. A preliminary search was conducted with assistance of a clinical librarian to develop our search strategy and specify our keywords. We used both free text and MeSH (MEDLINE) or thesaurus (Embase and PsycINFO) terms on the following subjects: physicians, occupational well-being, and quality of patient care.

Occupational well-being was defined as a positive experience with or evaluation of work $[12,13]$ and was searched with the terms job satisfaction, career satisfaction, professional satisfaction, job commitment, and work engagement. To reduce the chance of missing any relevant articles, we also included several synonyms (see Additional file).

We used the definition for quality of care provided in a framework introduced by Donabedian (1966) [25] which is widely used in quality of care research [26]. The framework distinguishes three elements of patient care quality: the quality of the structures (organizational factors of the health care system), processes (actual delivery of patient care), and outcomes of patient care (consequences of delivered care) [25]. For this review, we only included processes and outcomes of care, as the structure element of the Donabedian framework focuses on the system of patient care and not on individual physicians' delivery of patient care. Based on the definitions of processes and outcomes of patient care [25], we included the following search terms: patient centeredness, patient satisfaction, patient enablement, patient safety, and patient health outcomes (see Additional file). Finally, we performed a hand search on references of eligible articles to obtain additional eligible studies.

\section{Study Selection}

One author (RS) performed the search, which was duplicated by a clinical librarian. Subsequently, one author (RS) screened both title and abstract. Clearly, irrelevant studies were excluded at this point when both title and abstract did not include physicians, occupational well-being, or quality of patient care. Non-empirical articles (letters, comments, and editorials) were also excluded at this stage.

After screening, titles and abstracts of the remaining studies were independently reviewed by two authors (RS and $\mathrm{BB}$ ). If 
abstracts were unavailable, the full-text article was retrieved and reviewed by one author (RS), following the same procedure as for the abstracts. If full text was unavailable as well, two authors (RS and BB) independently reviewed each title. Two authors (RS and BB) independently reviewed the full texts of all remaining articles. When no consensus was reached, a third author (KL) reviewed the article (for two studies in total).

\section{Data Extraction and Quality Assessment}

Data on study design, participants and setting, measures and measurements, and study findings were extracted by one author (RS) and duplicated by a second author (BB). When no consensus was reached, a third author (KL) assisted.

We used the Medical Education Research Study Quality Instrument (MERSQI) [27] to assess study quality on ten criteria: study design, number of institutions, response rate, type of data, internal structure, content validity, criterion validity, appropriateness and sophistication of data analyses, and outcome level. The ten MERSQI items form six domains, each with a maximum score of 3 . The possible total MERS QI score can range from 5 to 18 [27]. Validity evidence of the MERSQI showed to be strong [27, 28]. Two authors (RS and BB) independently scored five studies using the MERSQI criteria, after which they agreed upon a uniform scoring procedure.

\section{Data Synthesis and Analysis}

We intended to perform a meta-analysis to pool the findings of studies. However, meta-analyses can only yield valid results if the heterogeneity between studies is limited. In this review, the heterogeneity between studies was large, so no meta-analysis could be performed. We presented the findings of the individual studies descriptively in the text and tables. We categorized the different findings based on the different forms of occupational well-being as well as the different patient care quality categories of the Donabedian framework (see Tables 1 and 2).

\section{Results}

Search Results

The search yielded 5944 unique hits (see Fig. 1, flow chart). Screening of title and abstract resulted in 387 potentially eligible articles. After abstract review, 89 articles remained and were independently reviewed and discussed on their full text. Finally, our systematic search resulted in 18 included articles. Hand search did not result in additional articles.
Table 1 Number of studies on MERSQI criteria

\begin{tabular}{|c|c|}
\hline MERSQI criteria & $\begin{array}{l}\text { Number of } \\
\text { studies }\end{array}$ \\
\hline Total of included studies & 18 \\
\hline \multicolumn{2}{|l|}{ Study design } \\
\hline Single group cross-sectional & 17 \\
\hline Single group pretest and posttest & 1 \\
\hline Non-randomized, two groups & - \\
\hline Randomized controlled experiment & - \\
\hline \multicolumn{2}{|l|}{ Institutions } \\
\hline Single institution & 1 \\
\hline Two institutions & - \\
\hline More than two institutions & 17 \\
\hline \multicolumn{2}{|l|}{ Response rate } \\
\hline$<50 \%$ OR not reported & 3 \\
\hline $50-74 \%$ & 8 \\
\hline $75-100 \%$ & 7 \\
\hline \multicolumn{2}{|l|}{ Type of data } \\
\hline Assessment by study object & 18 \\
\hline Objective measurement & - \\
\hline \multicolumn{2}{|c|}{$\begin{array}{l}\text { Internal structure (internal consistency, interrater reliability, factor } \\
\text { analysis) }\end{array}$} \\
\hline Not reported & 11 \\
\hline Reported & 7 \\
\hline \multicolumn{2}{|l|}{ Content validity } \\
\hline Not reported & 11 \\
\hline Reported & 7 \\
\hline \multicolumn{2}{|c|}{ Relations to other variables (criterion, concurrent, and predictive validity) } \\
\hline Not reported & 10 \\
\hline Reported & 8 \\
\hline \multicolumn{2}{|l|}{ Appropriateness of data analysis } \\
\hline $\begin{array}{l}\text { Data analysis inappropriate for study design or type of } \\
\text { data }\end{array}$ & 2 \\
\hline Data analysis appropriate for study design or type of data & 16 \\
\hline \multicolumn{2}{|l|}{ Sophistication of data analysis } \\
\hline $\begin{array}{l}\text { Descriptive statistics only (frequencies, measures of } \\
\text { central tendency) }\end{array}$ & 2 \\
\hline $\begin{array}{l}\text { Beyond descriptive analysis (comparisons, correlations, } \\
\text { relationships between variables) }\end{array}$ & 16 \\
\hline \multicolumn{2}{|l|}{ Highest outcome level } \\
\hline Satisfaction, attitudes, perceptions & 12 \\
\hline Knowledge, skills & - \\
\hline Behaviors & 6 \\
\hline Patient/health care outcomes & - \\
\hline
\end{tabular}

Study Quality

The quality of studies ranged between 6.5 and 13 on the MERSQI scale, and the average quality was 9.8 (Table 1). Most studies had a cross-sectional design and included more than two medical centers (17 studies [29-46], see Table 1). Seven studies had a high response rate (75-100\%) [33, 34, 
Table 2 Overview on the direction of the effects of occupational well-being on aspects of patient care quality found in the eligible studies

\begin{tabular}{|c|c|c|c|c|c|c|}
\hline & \multicolumn{5}{|l|}{ Processes of care } & \multirow{2}{*}{$\begin{array}{l}\text { Outcomes of care } \\
\text { Patient health }\end{array}$} \\
\hline & Technical aspects & $\begin{array}{l}\text { Interpersonal } \\
\text { aspects }\end{array}$ & Patient satisfaction & $\begin{array}{l}\text { Patient adherence to } \\
\text { treatment }\end{array}$ & Overall processes & \\
\hline \multirow{6}{*}{$\begin{array}{l}\text { Positive } \\
\quad \text { association }\end{array}$} & Job satisfaction & & & & & \\
\hline & $\begin{array}{l}\text { Melville et al. [29] } \\
\text { Williams et al. [30] }\end{array}$ & $\begin{array}{l}\text { Grol et al. [31] } \\
\text { Perez-Carceles et al. } \\
\quad[32]\end{array}$ & $\begin{array}{l}\text { Grembrowski et al. } \\
\quad[33] \\
\text { Haas et al. [34] } \\
\text { Mache et al. [35] } \\
\text { Szenenyi et al. [36] }\end{array}$ & Dimatteo et al. [37] & $\begin{array}{l}\text { Conway et al. } \\
{[38]} \\
\text { Williams et al. } \\
{[30]}\end{array}$ & - \\
\hline & Career satisfaction & & & & & \\
\hline & Frank et al. [39] & & DeVoe et al. [40] & - & $\begin{array}{l}\text { Deshpande et al. } \\
\text { [41] }\end{array}$ & - \\
\hline & Work engagement & & & & & \\
\hline & Prins et al. [42] & - & - & - & - & - \\
\hline \multirow[t]{2}{*}{ No association } & Job satisfaction & & & & & \\
\hline & $\begin{array}{l}\text { Grol et al. [31] } \\
\text { Linzer et al. [43] } \\
\text { Utsugi-Ozaki et al. } \\
\quad[44] \\
\text { Winefield et al. [45] }\end{array}$ & - & Weng et al. [46] & - & & $\begin{array}{l}\text { Grembrowski et al. } \\
\text { [33] }\end{array}$ \\
\hline $\begin{array}{l}\text { Negative } \\
\quad \text { association }\end{array}$ & - & - & - & - & - & - \\
\hline
\end{tabular}

Studies that appear more than once in this table analyzed multiple associations between multiple variables

$36,41,43-45]$, eight studies had a response rate between 50 and $75 \%[29,31,32,35,37,39,40,46]$, and three studies had a response lower than $50 \%$ or did not report it at all $[30,38$, 42]. Furthermore, seven studies reported internal structure of the measures on occupational well-being [29, 36, 38, 42, 45-47]. For patient care measures, seven studies used patient-reported data [33-37, 40, 46], seven studies used self-reported data [30, 32, 38, 39, 41, 42, 45], two studies used medical records [29, 44], and two studies used observations $[31,43]$. We reported the study outcomes descriptively, with detailed quantitative results of individual studies (Table 3).

\section{Study Characteristics}

The eligible studies included physicians across specialties: family medicine (nine studies [29-33, 36, 37, 43, 45]), internal medicine (four studies [34, 43, 44, 46]), and surgery (one study [35]), and five studies included a broad sample of physicians across specialties [38-42] (one study sampled both primary care and internal medicine physicians). Nine studies came from the USA [30, 33, 34, 37-40, 43], six studies came from Europe (Germany [35], Spain [32], the Netherlands [42], and the UK [29]), two studies came from Asia (Japan [44] and
Taiwan [46]), and one study came from Australia [45] (Table 3).

Occupational well-being was measured with the following constructs: job satisfaction (14 studies) [29-38, 43-46], career satisfaction (three studies) [39-41], and work engagement (one study) [42]. With regard to patient care, 17 studies used process measures [29-46], which focused on technical aspects of care (e.g., medication errors) [29-31, 43-45], interpersonal aspects of care (e.g., clearly explaining treatment to patients) [31, 32], overall processes (a combination of technical and interpersonal aspects of care) [30, 38, 41], patient satisfaction [33-36, 40, 46], and patient adherence to treatment [37] (see Table 3). One study used both processes and outcomes as measures for patient care quality [33].

\section{Occupational Well-Being and Quality of Patient Care}

Given the diversity of included studies, we presented an overview of the direction of the study results in Table 2. The detailed results per study are presented in Table 3 .

Eight studies reported on occupational well-being in relation to technical aspects of patient care. These showed contrasting results. Specifically, physicians with higher levels of 


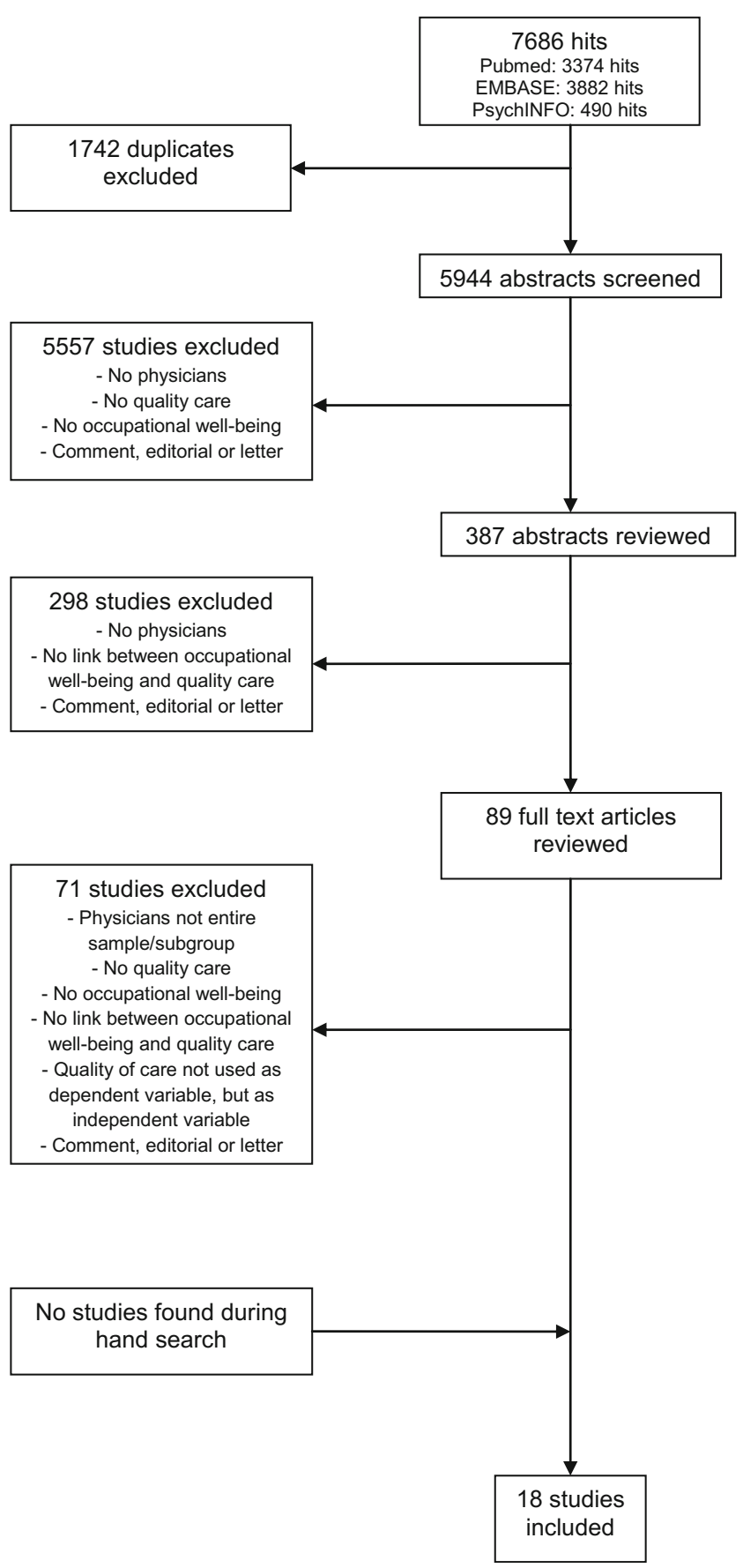

Fig. 1 Flow chart of the review process

occupational well-being reported less medical errors in two studies [30, 42], while these associations were not reported in two other studies on this topic $[43,45]$. In addition, physicians' job satisfaction was not associated with avoidant or superfluous medical care in consultations [31]. Another study showed that satisfied physicians prescribed less medicine which are considered indicators of incautious prescribing [29]. Two studies showed that satisfied physicians were not more likely to perform adequate clinical procedures for hypertension patients, diabetes patients $[43,44]$, asthma patients, or crosscutting care [44]. Physicians satisfied with their career were more likely to counsel 50-75-year-old patients regarding mammography [39], which can be considered a quality aspect of prevention as these involve a risk group for developing breast cancer (Table 3).

With regard to interpersonal aspects of patient care, family physicians who were satisfied with their work were more open to the patient and paid more attention to psychosocial aspects [31] (see Table 3). In addition, satisfied physicians informed their patients more frequently about diagnosis, prognosis, treatment, complementary examinations, and the work and social/family impact of the illness process [32].

Five studies showed positive associations between physicians' job or career satisfaction and patient satisfaction in various specialties, i.e., family medicine, internal medicine, and surgery [33-36, 40]. Furthermore, one study on patient adherence showed that patients of satisfied physicians adhered better to recommended medication, exercise, and diet than patients of physicians who were dissatisfied with their work [37]. Another study reported no associations between physicians' job satisfaction and patient satisfaction [46] (Table 3).

Physicians with higher levels of job satisfaction reported less suboptimal care (i.e., inadequate patient discharge, not performing a diagnostic test because of patients' desires, medication errors, and a lack of discussion of treatment with patients) [30]. Congruently, two studies showed that satisfied physicians reported better patient care quality than physicians who were less satisfied [38, 41].

One study researched occupational well-being in relation to patient health outcomes. This study showed that job satisfaction of physicians was not associated with patients' selfreported pain and depressive symptoms [33].

\section{Discussion}

This systematic review indicates that occupational well-being could positively contribute to patient satisfaction [33-36, 40], patient adherence to treatment [37], interpersonal aspects of patient care [31,32], and the quality of overall care processes $[30,38,41]$. Contrasting findings were reported by studies on physicians' occupational well-being and technical aspects of patient care [29-31, 39, 42-45]. The association between physicians' occupational well-being and patient health outcomes is underexplored up till date [33].

\section{Explanation of Findings}

The findings of this review indicate that patients of physicians with high levels of occupational well-being were more satisfied with their treatment [33-36, 40] and adhered better to treatment guidelines [37]. Physicians with higher levels of occupational well-being have a positive attitude toward work and are more 


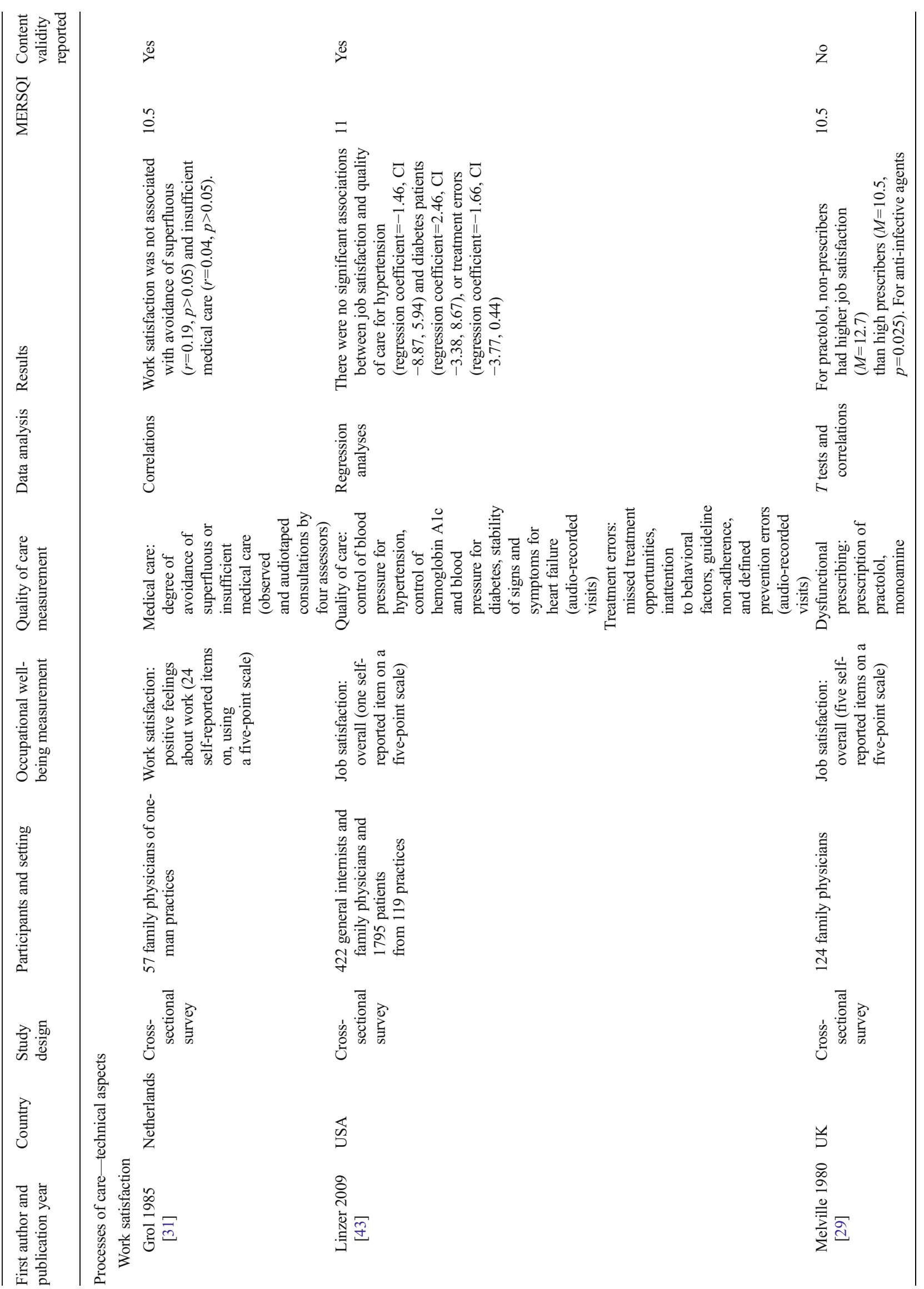




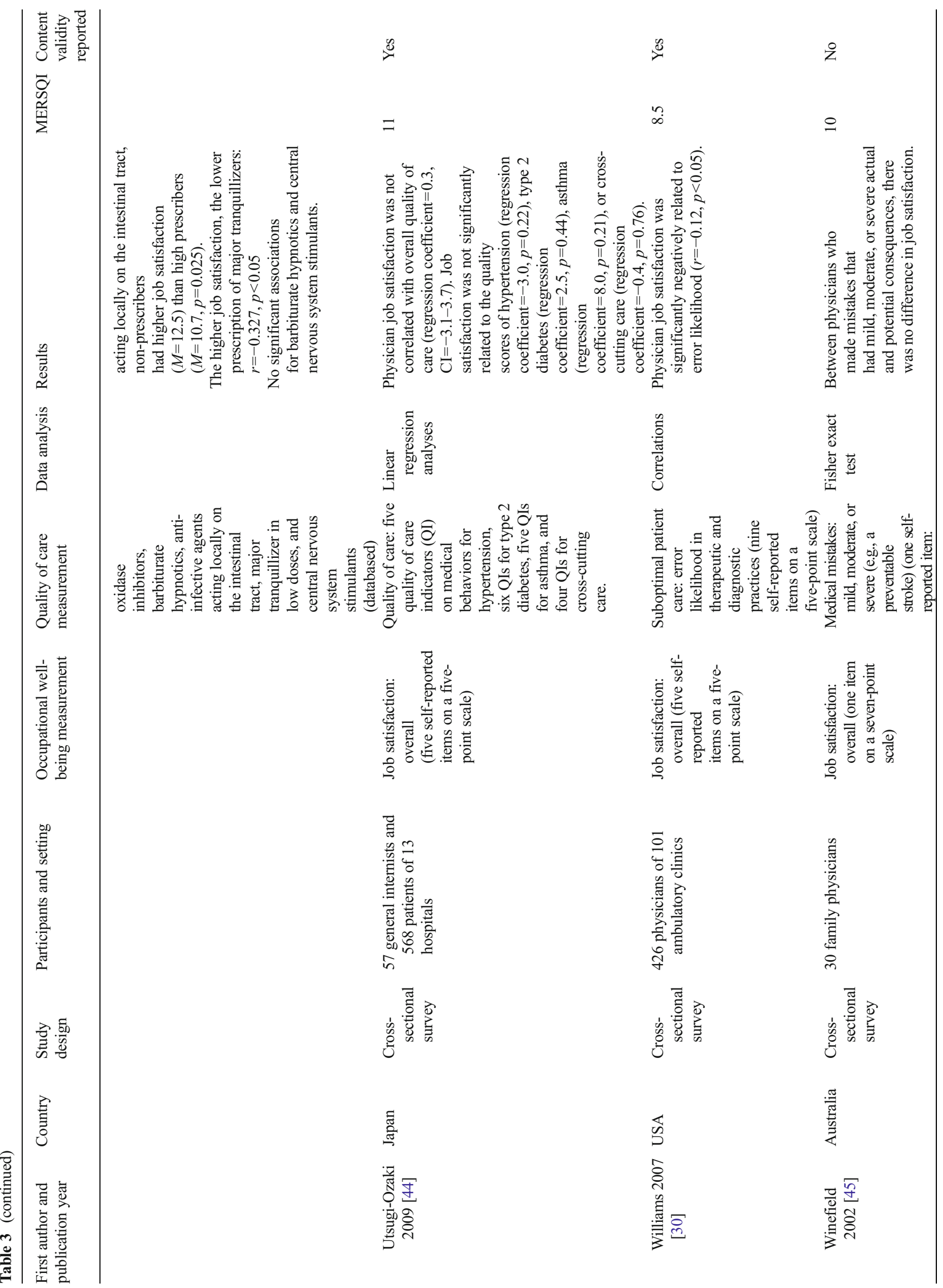




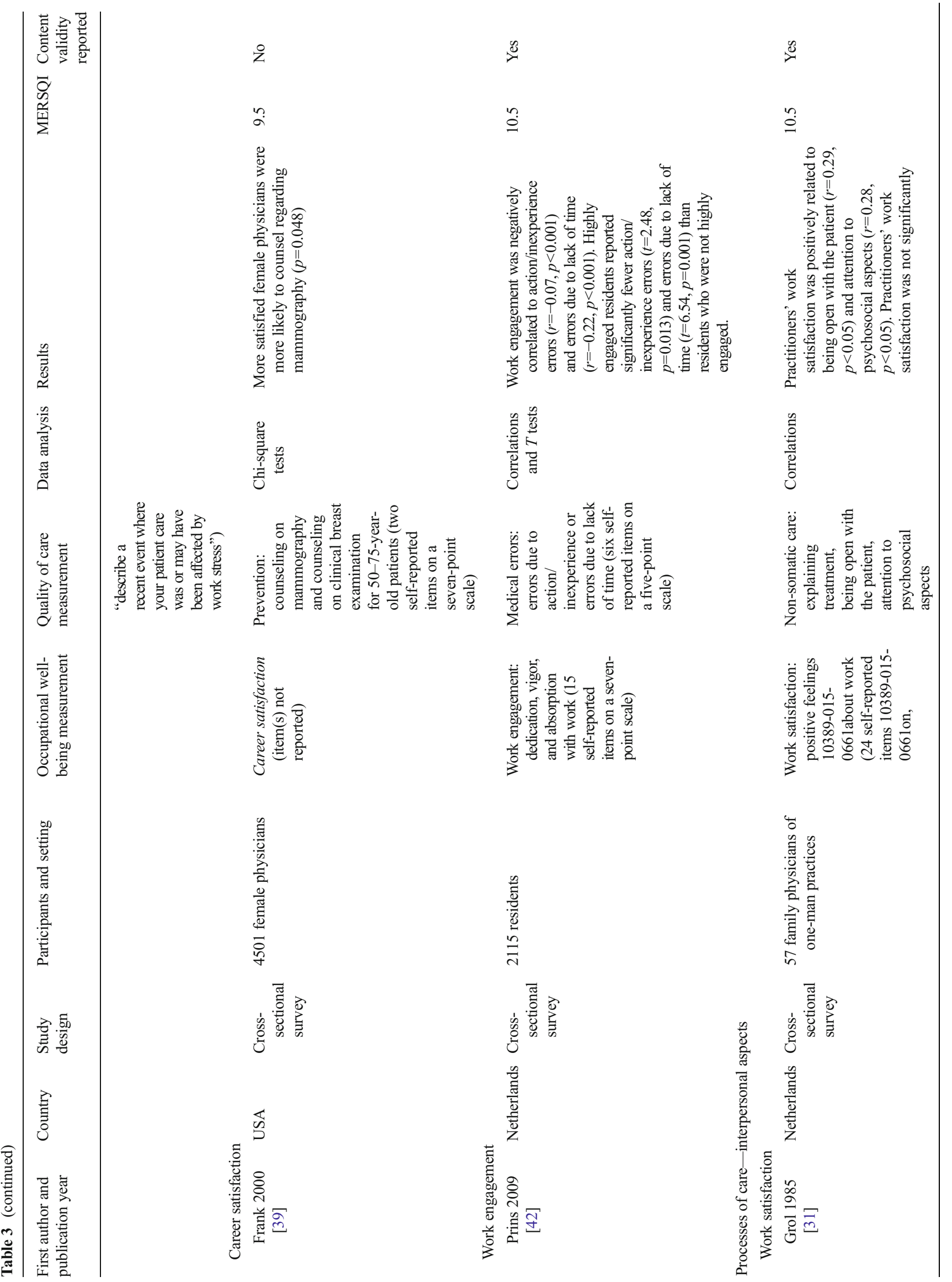




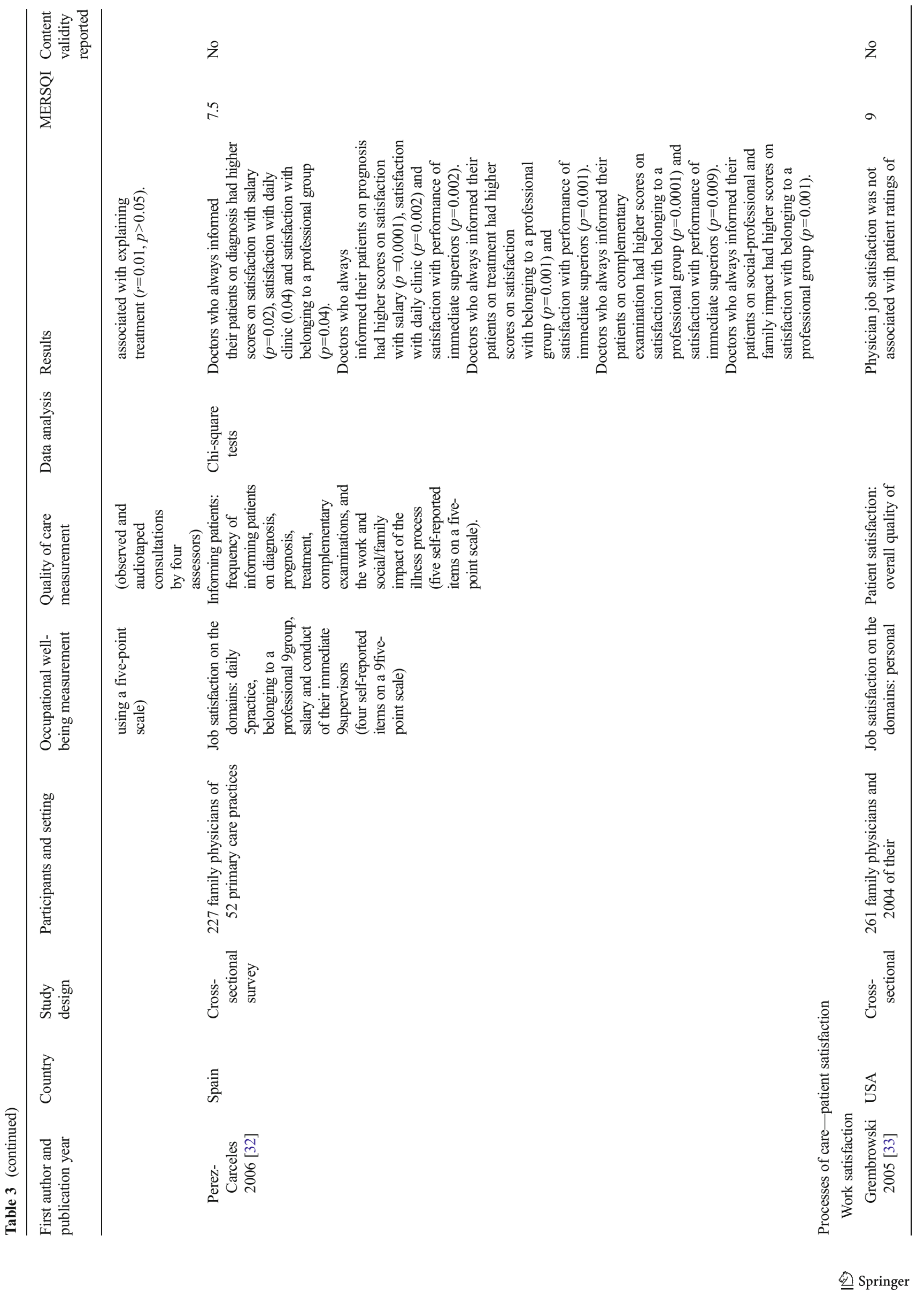




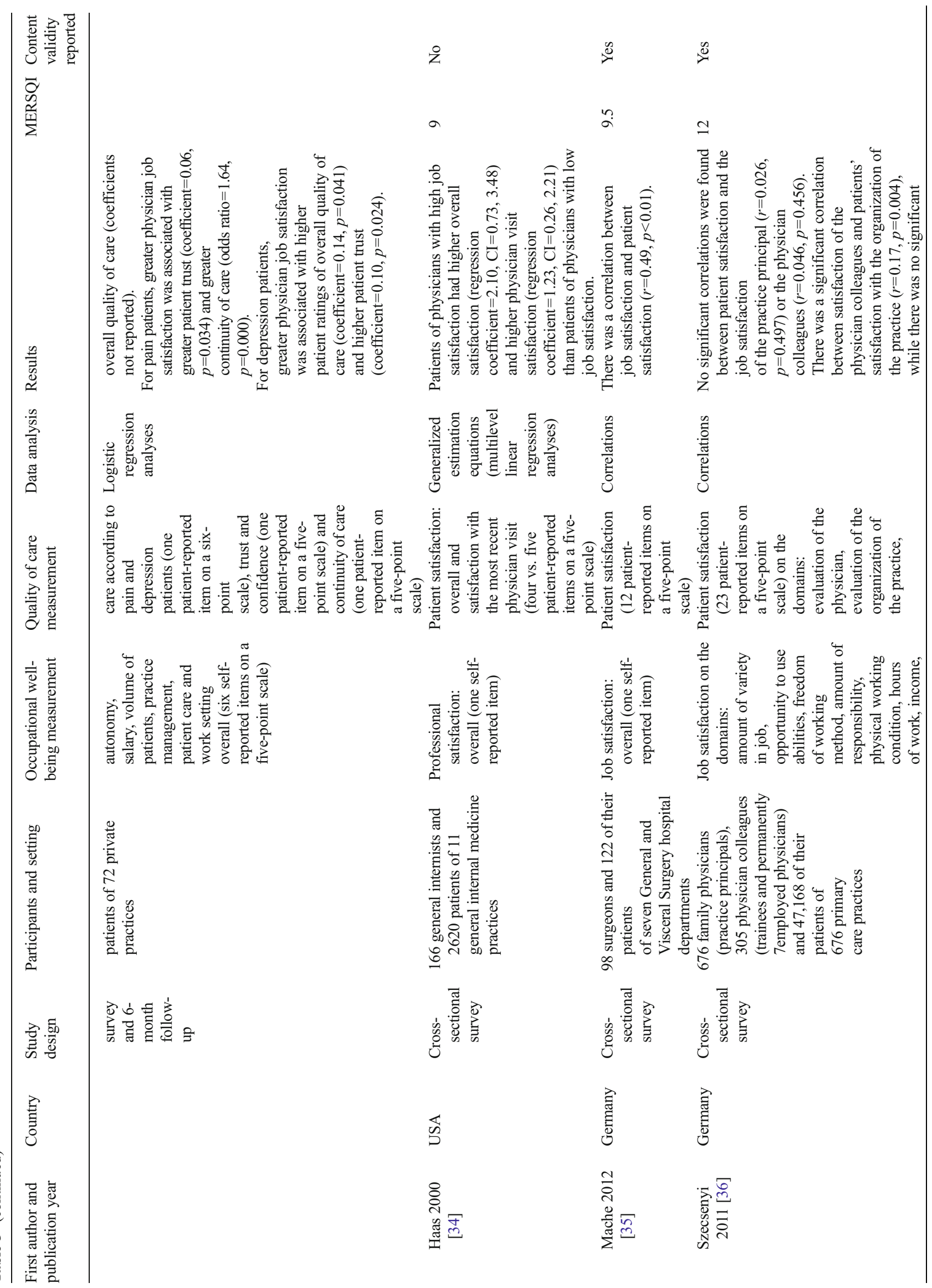




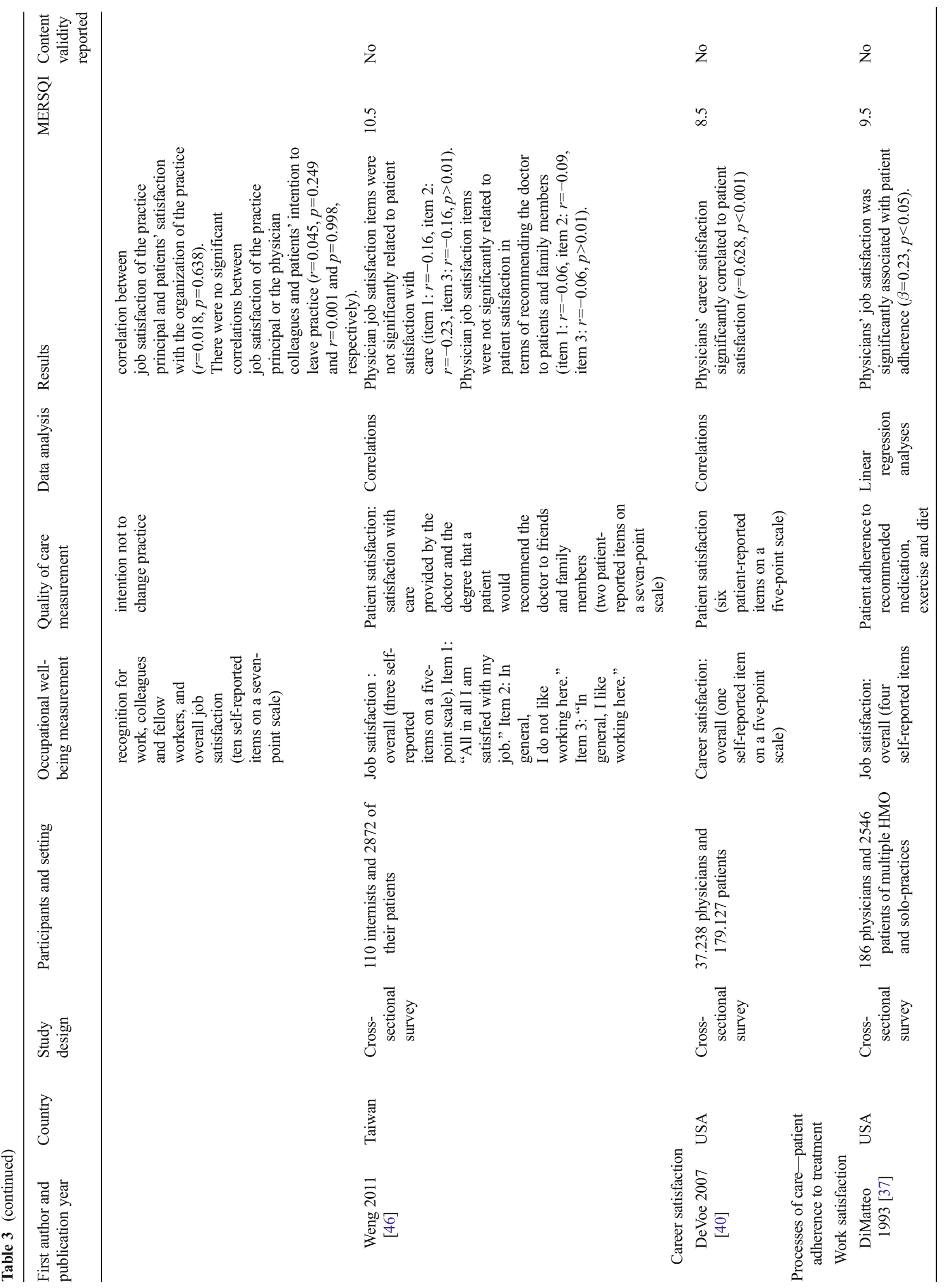




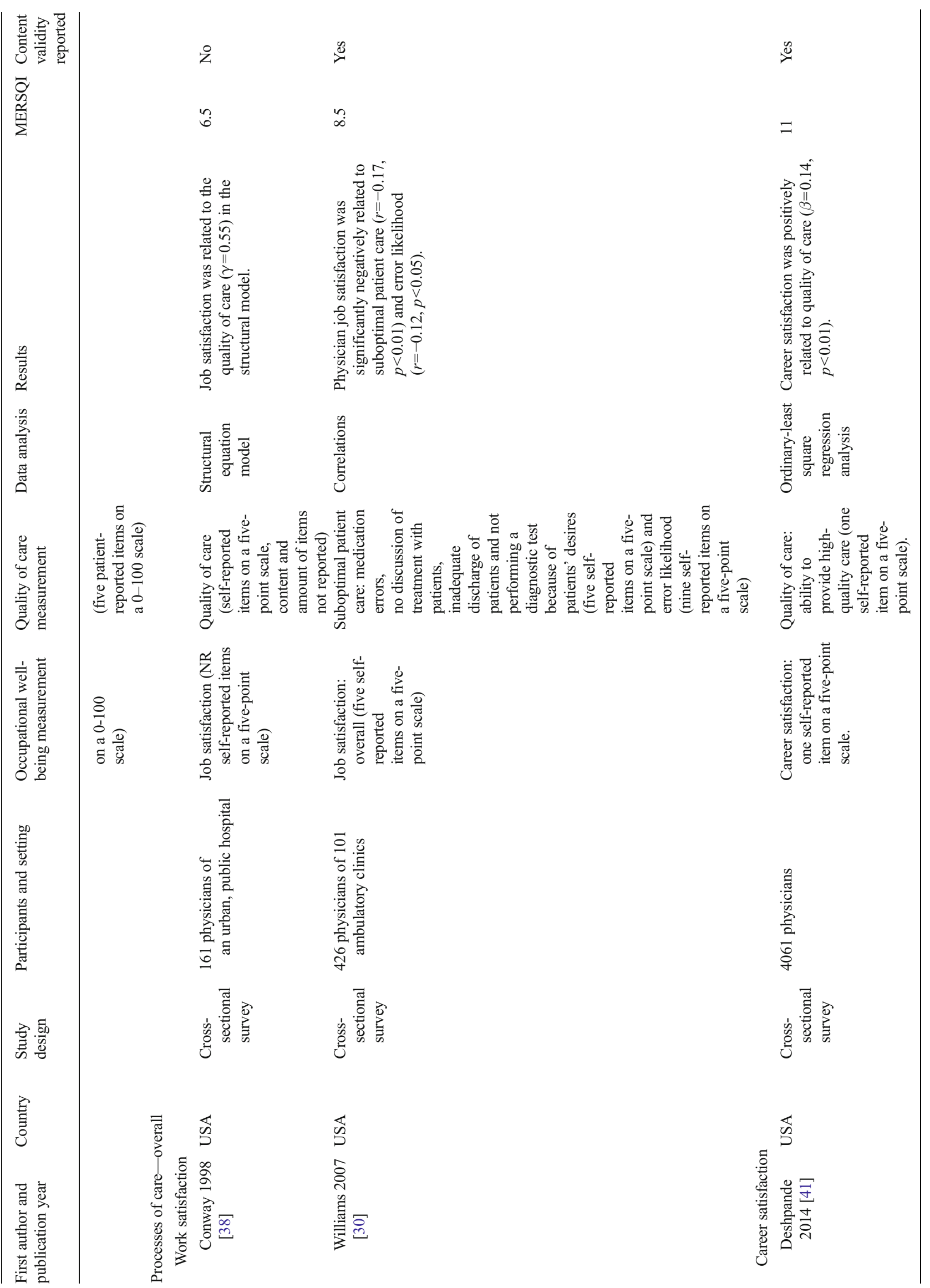


likely to be optimistic and helpful to others [20]. Possibly, more satisfied and engaged physicians cross over their optimism and positive attitude to patients $[48,49][48,49]$ and leave the patient more satisfied and motivated to follow up on treatment recommendations. Ultimately, better adherence to treatment recommendations indirectly contributes to better health and wellbeing of patients [50]. Positive effects of occupational wellbeing are also visible in other health care professions. Research reported that, according to their supervisors, nurses engaged with their work perform better [51]. Also, on the long term, work engagement showed to benefit work performance [52] .

As physicians with high levels of occupational well-being experience less stress and more positive emotions [12, 13, 20], they have more energy and mental resources to direct full attention to patients. This resonates with our findings that physicians who experience high levels of occupational well-being are likely to direct more attention to patients' psychosocial aspects [31] and inform them more frequently about the process of care and on the social impact of the illness process [32]. Also, other research showed that physicians' well-being may positively influence interpersonal aspects of patient care, as physicians with positive affect generally talk more with patients [53].

Ultimately, the health care system is targeted at achieving better health and well-being for patients [50]. A vital and engaged physician workforce is thought to be one of the conditions under which optimal patient care can take place [2]. Strikingly, research so far failed to clarify the impact of physicians' occupational well-being on health care's ultimate goal-improved health of patients. In particular, only one study attempted to elucidate this issue. This study showed that occupational wellbeing did not affect pain and depressive symptoms of patients [33]. As this is only one study, clearly, more research is needed to draw nuanced conclusions on the impact of occupational well-being on patient health outcomes. This research could consider to involve both processes and outcomes of care, as it is reasonable to assume that occupational well-being directly affects care processes, i.e., physicians' behaviors, which ultimately contribute to patients' health.

Although most research on occupational well-being in relation to aspects of patient care quality shows rather consistent results, findings for technical aspects of patient care were conflicting. Technical aspects of patient care refer to all medical or clinical behaviors that physicians undertake in their treatment for patients, i.e., prescribing medicine or performing a physical examination [25]. Our review indicates that physicians with high levels of occupational well-being show more adequate prescribing behavior [29]. Previous research-outside the scope of this review - showed that physicians with higher levels of well-being (in terms of positive affect) prescribed less medicine to patients [53]. Nonetheless, higher levels of occupational well-being did not prevent physicians from delivering superfluous medical care, i.e., care which is not necessary according to the most recent standards [31]. Other 
conflicting findings were also reported for technical aspects of patient care in terms of medical errors, as two studies showed positive associations of physicians' occupational well-being with medical errors [30, 42] and two others did not [43, 45]. This could be due to the variation in measures, as medical errors may refer to various contents, ranging from missed diagnoses to guideline non-adherence. Future research on occupational well-being could benefit from standardized measures on technical aspects of patient care.

Some studies in this review studied specific aspects of patient care (i.e., informing patients); others reported overall patient care quality and did not specify the specific content or aspects of patient care quality [30, 38, 41]. These studies on overall quality consistently showed that physicians with higher levels of occupational well-being report better quality of patient care. More than the other studies included in this review, these studies used self-reported measures for patient care quality. Therefore, these findings should be interpreted with caution, as these findings could possibly be associated with so-called rose-colored glasses [54]. That is, a general positive attitude of physicians with higher levels of occupational well-being could account for the following positive perception of their own delivery of care [55]. Nonetheless, these findings on the positive impact of occupational well-being resonate with a previous review on negative consequences of physicians' lack of wellbeing [2]. That is, as previous research reported negative consequences of physicians' lack of well-being on the quality of care [2], it is not unreasonable to assume that the presence of physicians' occupational well-being indeed induces positive effects on overall quality of care [56].

The majority of the included studies in this review focused on job satisfaction as a measure of occupational well-being; other forms of occupational well-being are understudied. For example, we only found one study on work engagement. Compared to job satisfaction, other forms of occupational well-being such as work engagement, have shown to induce larger effects on work performance in non-medical professions [57], therefore, more extensive research on these forms may be relevant for clinical practice.

\section{Limitations}

Like many systematic reviews, our review could have suffered from publication bias [24]. Based on the MERSQI quality criteria, we could conclude that most studies were of average quality [27] and many studies were multicenter, showed reasonable response rates, and used validated measurements. Yet, some studies had limitations, such as the use of physicians' self-reported data of patient care delivery [54]. In addition, the heterogeneity of measures of occupational well-being was large, hindering comparison of results and meta-analysis. On the other hand, both occupational well-being and quality of patient care are not one-dimensional constructs. Therefore, the heterogeneity provided a multifaceted view on occupational well-being in relation to the quality of patient care.

We included studies from many countries and different health systems. Because of the differences between health care systems, the working conditions of physicians and, ultimately, their occupational well-being could differ between systems $[58,59]$. The aim of this study was to present an overview of the empirical literature on physicians' occupational wellbeing in relation to quality of care. Additional research is needed to understand the (possible) variations in this link across health care systems.

\section{Implications}

In the last decade, research and society increasingly focused on the prevention of burnout or other negative forms of physician well-being, in order to prevent physicians from delivering suboptimal patient care [2]. As an addition hereupon, this review yields starting points to enhance quality of patient care by mapping the effects of positive occupational well-being. Following the findings of this systematic review, patient satisfaction, patient adherence to treatment recommendations, and interpersonal aspects of patient care are most likely to benefit from increased occupational well-being of physicians. To that end, health care organizations could focus on creating optimal working conditions for physicians, possibly beneficial for their occupational well-being and, ultimately, quality of patient care. Future research could facilitate this process, by studying which specific working conditions positively contribute to occupational well-being of physicians. Although research already systematically summarized studies on the working conditions, work hours, shift length, night float, and protected sleep time $[60,61]$, there is little research on the effects of many other influential working conditions in medical practice (e.g., performance feedback and autonomy).

As patient care can increasingly be characterized by multidisciplinary teamwork $[62,63]$, future research could focus on how levels of occupational well-being among team members interact in producing better patient care. Positive feelings about work appear to cross over between colleagues in work teams $[64,65]$ and might boost quality of teamwork $[66]$.

\section{Conclusions}

Although there is substantial research on potential consequences of physicians' well-being, the impact on patient care's central goal-improved patient health-remains understudied. Nonetheless, research provided clarity on the association of occupational well-being with other aspects of patient care quality. This research found that physicians' occupational well-being could positively contribute to patient satisfaction and the quality of interpersonal aspects of care. 
Therefore, physicians' occupational well-being not only is vital to a healthy physician workforce, but also may contribute to better treatment and positive experiences of patients [50].

Acknowledgments We would like to thank Prof. Taris in particular for his expert opinion on the design of the study. We are grateful to Milou Silkens and Alina Smirnova, who helped us in the review process. We would like to thank the Journal Club and the Professional Performance research group at the Academic Medical Center of the University of Amsterdam for their stimulating feedback. This work was supported by the Dutch Ministry of Health, which cofinanced the research project Quality of Clinical Teachers and Residency Training Programs together with the Academic Medical Centre, Amsterdam, and the Faculty of Health and Life Sciences of the University of Maastricht.

Conflict of Interest Funders had no role in study design, data collection, data analysis, data interpretation, or writing of the report. Authors R.A. Scheepers, O.A. Arah, M.J. Heineman, and M.J.M.H Lombarts declare that they have no conflict of interests. This review investigated and synthesized previously published studies; no animal or human subjects were studied for this article.

Open Access This article is distributed under the terms of the Creative Commons Attribution License which permits any use, distribution, and reproduction in any medium, provided the original author(s) and the source are credited.

\section{References}

1. Tsutsumi A. Occupational health—items on the research agenda. Int J Behav Med 2011. Springer US. 2011;293-4.

2. Wallace JE, Lemaire JB, Ghali WA. Physician wellness: a missing quality indicator. Lancet. 2009;374(9702):1714-21.

3. Prins JT, Gazendam-Donofrio SM, Tubben BJ, Van Der Heijden FM, Van De Wiel H, Hoekstra-Weebers JE. Burnout in medical residents: a review. Med Educ. 2007;41(8):788-800.

4. Prins JT, Hoekstra-Weebers J, Van de Wiel H, et al. Burnout among Dutch medical residents. Int J Behav Med. 2007;14(3):119-25.

5. Dyrbye LN, Varkey P, Boone SL, Satele DV, Sloan JA, Shanafelt TD, editors. Physician satisfaction and burnout at different career stages. Mayo Clin Proc. 2013; doi:10.1016/j.mayocp.2013.07.016.

6. Shanafelt TD, Balch CM, Bechamps G, et al. Burnout and medical errors among American surgeons. Ann Surg. 2010;251(6):995-1000.

7. Shanafelt TD, Bradley KA, Wipf JE, Back AL. Burnout and selfreported patient care in an internal medicine residency program. Ann Intern Med. 2002;136(5):358-67.

8. Halbesleben JRB, Rathert C. Linking physician burnout and patient outcomes: exploring physicians and patients. Health Care Manag Rev. 2008;33(1):29-39.

9. Williams ES, Skinner AC. Outcomes of physician job satisfaction: a narrative review, implications, and directions for future research. Health Care Manag Rev. 2003;28(2):119-39.

10. van den Hombergh P, Kunzi B, Elwyn G, et al. High workload and job stress are associated with lower practice performance in general practice: an observational study in 239 general practices in the Netherlands. BMC Health Serv Res. 2009;9:118.

11. Linn LS, Brook RH, Clark VA, Davies AR, Fink A, Kosecoff J. Physician and patient satisfaction as factors related to the organization of internal medicine group practices. Med Care. 1985;23(10):1171-8.

12. Horn JE, Taris TW, Schaufeli WB, Schreurs PJG. The structure of occupational well-being: a study among Dutch teachers. J Occup Organ Psychol. 2004;77(3):365-75.

13. Xanthopoulou D, Bakker AB, Ilies R. Everyday working life: explaining within-person fluctuations in employee well-being. Hum Relat. 2012;65(9):1051-69.

14. Mathieu JE, Farr JL. Further evidence for the discriminant validity of measures of organizational commitment, job involvement, and job satisfaction. J Appl Psychol. 1991;76(1):127-33.

15. Hallberg UE, Schaufeli WB. "Same same" but different? Eur Psychol. 2006;11(2):119-27.

16. Schaufeli WB, Taris TW, Van Rhenen W. Workaholism, burnout, and work engagement: three of a kind or three different kinds of employee well-being? Appl Psychol. 2008;57(2):173-203.

17. Bovier PA, Perneger TV. Predictors of work satisfaction among physicians. Eur J Pub Health. 2003;13(4):299-305.

18. Rizvi R, Raymer L, Kunik M, Fisher J. Facets of career satisfaction for women physicians in the United States: a systematic review. Women \& Health; 3/28/2012: Routledge; 2012. p. 403-21.

19. Scheurer D, McKean S, Miller J, Wetterneck T. U.S. physician satisfaction: a systematic review. J Hosp Med. 2009;4(9):560-8.

20. Prins JT, Hoekstra-Weebers JEHM, Gazendam-Donofrio SM, et al. Burnout and engagement among resident doctors in the Netherlands: a national study. Med Educ. 2010;44(3):236- 47.

21. Luthans F. The need for and meaning of positive organizational behavior. J Organ Behav. 2002;23(6):695-706.

22. Luthans F. Positive organizational behavior: developing and managing psychological strengths. Acad Manag Exec. 2002;16(1):57-72.

23. Demerouti E, Taris TW, Bakker AB. Need for recovery, home-work interference and performance: is lack of concentration the link? J Vocat Behav. 2007;71(2):204-20.

24. Moher D, Liberati A, Tetzlaff J, Altman DG. Preferred reporting items for systematic reviews and meta-analyses: the PRISMA statement. J Clin Epidemiol. 2009.

25. Campbell SM, Roland MO, Buetow SA. Defining quality of care. Soc Sci Med. 2000;51:1611-25.

26. Lazar EJ, Fleischut P, Regan BK. Quality measurement in healthcare. Annu Rev Med. 2013. doi:10.1146/annurev-med-061511-135544.

27. Reed DA, Cook DA, Beckman TJ, Levine RB, Kern DE, Wright SM. Association between funding and quality of published medical education research. JAMA. 2007;298(9):1002-9.

28. Reed DA, Beckman TJ, Wright SM, Levine RB, Kern DE, Cook DA. Predictive validity evidence for medical education research study quality instrument scores: quality of submissions to JGIM's Medical Education Special Issue. J Gen Intern Med. 2008;23(7): 903-7.

29. Melville A. Job satisfaction in general practice: implications for prescribing. Soc Sci Med. 1980;14A:495-9.

30. Williams ES, Manwell LB, Konrad TR, Linzer M. The relationship of organizational culture, stress, satisfaction, and burnout with physician-reported error and suboptimal patient care: results from the MEMO study. Health Care Manag Rev. 2007;32(3):203-12.

31. Grol R, Mokkink H, Smits A, et al. Work satisfaction of general practitioners and the quality of patient care. Fam Pract. 1985;2(3): 128-35.

32. Perez-Carceles JE, Perenigues-Barranco EOCA, Luna-Maldonado A. The patient's right to information: influence of socioprofessional factors in primary care. Aten Primaria. 2006;37(2):69 77.

33. Grembowski D, Paschane D, Diehr P, Katon W, Martin D, Patrick DL. Managed care, physician job satisfaction, and the quality of primary care. J Gen Intern Med. 2005;20(3):271-7. 
34. Haas JS, Cook EF, Puopolo AL, Burstin HR, Cleary PD, Brennan TA. Is the professional satisfaction of general internists associated with patient satisfaction? J Gen Intern Med. 2000;15(2):122-8.

35. Mache S, Vitzthum K, Klapp BF, Groneberg DA. Improving quality of medical treatment and care: are surgeons' working conditions and job satisfaction associated to patient satisfaction? Langenbeck's Arch Surg. 2012;397(6):973-82.

36. Szecsenyi J, Goetz K, Campbell S, Broge B, Reuschenbach B, Wensing $\mathrm{M}$. Is the job satisfaction of primary care team members associated with patient satisfaction? BMJ Qual Saf. 2011;20(6):50814.

37. DiMatteo MR, Sherbourne CD, Hays RD, et al. Physicians' characteristics influence patient adherence to medical treatment: results from the medical outcomes study. Health Psychol. 1993;12(2):93102.

38. Conway T, Hu TC, Daugherty SR. Physicians' perceptions of managed care: a structural equation model assessment of key dimensions. Med Care. 1998;36(9):1430-5.

39. Frank E, Rimer BK, Brogan D, Elon L. U.S. women physicians' personal and clinical breast cancer screening practices. J Womens Health Gend Based Med. 2000;9(7):791-801.

40. DeVoe J, Fryer Jr GE, Straub A, McCann J, Fairbrother G. Congruent satisfaction: is there geographic correlation between patient and physician satisfaction? Med Care. 2007;45(1):88-94.

41. Deshpande SP, Deshpande SS. Antecedents of care by physicians. Health Care Manag. 2014;33(1):38-44.

42. Prins JT, van der Heijden FM, Hoekstra-Weebers JE, et al. Burnout, engagement and resident physicians' self-reported errors. Psychol Health Med. 2009;14(6):654-66.

43. Linzer M, Manwell LB, Williams ES, et al. Working conditions in primary care: physician reactions and care quality. Ann Intern Med. 2009;151(1):28-9.

44. Utsugi-Ozaki M, Bito S, Matsumura S, Hayashino Y, Fukuhara S. Physician job satisfaction and quality of care among hospital employed physicians in Japan. J Gen Intern Med. 2009;24(3):38792.

45. Winefield HR, Veale BM. Work stress and quality of work performance in Australian general practitioners. Aust J Prim Care. 2002;8(2).

46. Weng HC, Hung CM, Liu YT, et al. Associations between emotional intelligence and doctor burnout, job satisfaction and patient satisfaction. Med Educ. 2011;45(8):835-42.

47. Linzer M, Manwell LB, Mundt M, et al. Organizational climate, stress, and error in primary care: the MEMO study. Adv Patient Saf. 2005;1:65-77.

48. Wild B, Erb M, Bartels M. Are emotions contagious? Evoked emotions while viewing emotionally expressive faces: quality, quantity, time course and gender differences. Psychiatry Res. 2001;102(2): 109-24.

49. Bakker AB. Flow among music teachers and their students: the crossover of peak experiences. J of Vocational Behavior. 2005;66(1):2644.
50. Grol R. Improving the quality of medical care. JAMA. 2001;286(20): 2578-85.

51. Salanova M, Lorente L, Chambel MJ, Martínez IM. Linking transformational leadership to nurses' extra-role performance: the mediating role of self-efficacy and work engagement. J Adv Nurs. 2011;67(10):2256-66.

52. Shimazu A, Schaufeli WB, Kamiyama K, Kawakami N. Workaholism vs. work engagement: the two different predictors of future well-being and performance. Int J Behav Med. 2014;1-6.

53. Kushnir T, Kushnir J, Sarel A, Cohen AH. Exploring physician perceptions of the impact of emotions on behaviour during interactions with patients. Fam Pract. 2010.

54. Davis DA, Mazmanian PE, Fordis M, Van HR, Thorpe KE, Perrier L. Accuracy of physician self-assessment compared with observed measures of competence: a systematic review. JAMA. 2006;296(9): 1094-102. doi:10.1001/jama.296.9.1094.

55. Podsakoff PM, MacKenzie SB, Lee JY, Podsakoff NP. Common method biases in behavioral research: a critical review of the literature and recommended remedies. J Appl Psychol. 2003;88(5):879-903.

56. Xanthopoulou D, Bakker AB, Heuven E, Demerouti E, Schaufeli WB. Working in the sky: a diary study on work engagement among flight attendants. J Occup Health Psychol. 2008;13:345-56.

57. Christian MS, Garza AS, Slaughter JE. Work engagement: a quantitative review and test of its relations with task and contextual performance. Pers Psychol. 2011;64(1):89-136.

58. Aiken LH, Sloane DM, Clarke S, et al. Importance of work environments on hospital outcomes in nine countries. Int J Qual Health Care. 2011;23(4):357-64.

59. Hakanen JJ, Schaufeli WB, Ahola K. The job demands-resources model: a three-year cross-lagged study of burnout, depression, commitment, and work engagement. Work Stress. 2008;22(3):224-41.

60. Fletcher KE, Davis SQ, Underwood W, Mangrulkar RS, McMahon Jr LF, Saint S. Systematic review: effects of resident work hours on patient safety. Ann Intern Med. 2004;141(11):851-7.

61. Reed DA, Fletcher KE, Arora VM. Systematic review: association of shift length, protected sleep time, and night float with patient care, residents' health, and education. Ann Intern Med. 2010;153(12): 829-42.

62. Porter ME. A strategy for health care reform - toward a value-based system. N Engl J Med. 2009.

63. Leape L, Berwick D, Clancy C, et al. Transforming healthcare: a safety imperative. Qual Saf Health Care. 2009;18(6):424-8.

64. Bakker AB, Xanthopoulou D. The crossover of daily work engagement: test of an actor-partner interdependence model. J Appl Psychol. 2009;94:1562-71.

65. Bakker AB, van Emmerik H, Euwema MC. Crossover of burnout and engagement in work teams. Work Occup. 2006;33(4):464-89.

66. Mohr DC, Young GJ, Meterko M, Stolzmann KL, White B. Job satisfaction of primary care team members and quality of care. Am J Med Qual. 2011. doi:10.1177/1062860610373378. 